\title{
O TRABALHO PARASSUBORDINADO
}

\author{
Otávio Pinto e Silva \\ Professor Assistente do Departamento de Direito do \\ Trabalho da Faculdade de Direito da \\ Universidade de São Paulo
}

\begin{abstract}
Resumo:
O presente artigo estuda o conceito de parassubordinação, desenvolvido pela doutrina italiana com o objetivo de efetuar uma distinção entre a subordinação e a autonomia nas relações jurídicas de trabalho. O setor da parassubordinação engloba relações de trabalho que, embora se desenvolvam com independência e sem a direção do destinatário dos serviços, se inserem de forma contínua na organização deste, justificando então uma tutela semelhante à dedicada aos empregados.
\end{abstract}

Abstract:

This article studies the parasubordination concept, developed by the Italian doctrine in order to distinguish subordination from autonomy in the legal labor relations. The parasubordination sector involves labor relations that are continuously included in the organization of the services receivers, a fact that justifies a legal protection similar to the one destined to employees, even though the development of those relations is neither dependent on nor directed by the receivers of such services.

Unitermos: subordinação; autonomia; parassubordinação; relação de trabalho.

\section{Introdução.}

A noção de parassubordinação foi desenvolvida pela doutrina italiana, tendo em vista uma série de relações jurídicas heterogêneas que têm por objeto a prestação de trabalho.

São relações de trabalho de natureza contínua, nas quais os trabalhadores desenvolvem atividades que se enquadram nas necessidades organizacionais dos tomadores de seus serviços, tudo conforme estipulado em contrato, visando colaborar para os fins do empreendimento.

A tradução da palavra parasubordinazione do italiano para o português é literalmente parassubordinação, uma vez que o prefixo $\operatorname{par}(a)$ é usado em composição que reveste a noção "para além de" ' No caso, resulta portanto em "para além da subordinação" 
Para o Direito brasileiro mostra-se oportuno o estudo desse conceito com o objetivo de aperfeiçoamento de nosso sistema de relações de trabalho, de modo a "ir além" da subordinação própria dos empregados e incluir no campo do Direito do Trabalho novas situações decorrentes da modernização das formas de produção.

2. Parassubordinação.

O Direito italiano abriga no conceito de parassubordinação diferentes tipos de relações jurídicas, que conservam sua específica disciplina substancial, conforme cada caso.

Essas relações jurídicas recebem ainda uma regulamentação suplementar, formalizada por lei ou por contrato coletivo, que garante algumas medidas de proteção.

Sob o aspecto da tutela processual, todas as relações de trabalho parassubordinado ficam submetidas a trâmites idênticos aos que são previstos em lei para os empregados.

Nesse sentido, o art. 409, n. 3, do Codice de Procedura Civile (com a redação dada pela Lei n. 533, de 11 de agosto de 1973), prevê entre as relações jurídicas sujeitas ao rito processual trabalhista "rapporti di agenzia, di rappresentanza commerciale ed altri rapporti di collaborazione che si concretino in uma prestazione di opera continuativa e coordinata, prevalentemente personale, anche se non a carattere subordinato" 2

Conforme explica Giuseppe Ferraro, o elemento de conexão entre as várias relações de trabalho parassubordinado pode ser genericamente descrito como um vínculo de dependência substancial e de disparidade contratual que se estabelece entre o prestador dos serviços e o sujeito que usufrui dessa prestação. Esse vínculo de dependência é semelhante ao que une empregado e empregador, a ponto de justificar a existência de garantias compensatórias equivalentes. ${ }^{3}$

Para Giuseppe Tarzia, o amplo setor da parassubordinação engloba relações de trabalho que, embora se desenvolvam com independência e sem a direção do destinatário dos serviços, se inserem na organização deste. ${ }^{4}$

Com o reconhecimento da existência dessa classe de relações juridicas, a doutrina italiana procura deixar claro que:

a. o trabalho parassubordinado possui algumas semelhanças com o trabalho subordinado, mas com ele não se confunde;

b. a parassubordinação vai além do conceito tradicional de trabalho autônomo.

Por conceito tradicional de trabalho autônomo entende-se aquele formulado a partir das instituições de Direito Romano, segundo o qual nessa relação

2. "relaçōes de agência, de representação comercial e outras relações de colaboração que se expressam numa prestação de serviços continuada e coordenada, preférencialmente pessoal, ainda que sem caráter subordinado" - tradução livrc do autor

3. FERRARO, Giuscppe. I contratti di lavoro, Padova, CEDAM, 1991, p. 226

4. TARZIA, Giuscppc. Manuale del Processo del Lavoro, Milano, Giuffrè, 1987, p. 9 
de trabalho o trabalhador assume a obrigação de produzir um determinado resultado.

Essa obrigação, assim, está fadada a se extinguir no exato momento de sua execução e da conseqüente satisfação do interesse do contratante.

Porém, distinta é a situação em que o trabalhador assume a obrigação de atingir uma série de resultados consecutivos, coordenados entre si e relacionados a interesses mais amplos do contratante, interesses que não estão limitados aos que derivam de cada prestação individualmente considerada.

Vejamos, então, os elementos que estão presentes na relação juridica de trabalho parassubordinado.

3. Continuidade da prestação dos serviços.

O primeiro elemento é o da continuidade da relação de trabalho: a prestação de serviços deve se destinar a atender uma necessidade do tomador que tenha um determinado prolongamento no tempo, tendo em vista os interesses de ambas as partes.

Isso significa que não se enquadra no conceito de parassubordinação o contrato de obra de execução instantânea, ainda que prolongada no tempo, se a duração da prestação não estiver voltada a um programa comum, em que a organização da produção é consequiência da reunião dos interesses do trabalhador e do tomador dos serviços.

Vale dizer, o critério da continuidade é incompatível com a efetivação de uma única obra, ainda que para a sua execução se faça necessário um tempo não-breve.

Afinal de contas, a continuidade deve estar vinculada a uma série de resultados que as partes pretendem atingir e que justificam a presença da coordenação, como veremos adiante.

Ressalte-se ainda que a Jurisprudência italiana entende não estar caracterizada a continuidade quando a reiteração das prestações for meramente ocasional, ou quando for o resultado de contingências fáticas não-previstas (e nãopassíveis de previsão por ocasião da contratação de cada uma das prestações).

De tudo isso o que resta claro é que a continuidade está vinculada a necessidades que de certo modo possuem um caráter mais duradouro, sendo irrelevante a circunstância de que a prestação de trabalho não se desenvolva de forma exclusiva.

Também não afeta a continuidade a hipótese de que o trabalho prestado, por sua natureza, permita interrupções periódicas.

4. Pessoalidade na prestação dos serviços.

O segundo elemento caracterizador do trabalho parassubordinado é a natureza pessoal da prestação dos serviços, que deve preponderar.

O prestador dos serviços até pode se valer do auxílio de outras pessoas, mas dentro de certos limites. Sendo assim, o trabalho desses auxiliares deve ser apenas 
complementar, o que significa que a principal carga de atividades deve ser desenvolvida pelo prestador pessoalmente contratado.

Isso significa que o prestador dos serviços atua como um pequeno empreendedor, organizando em torno de si todas as atividades voltadas ao atendimento das necessidades do tomador.

5. Colaboração entre o trabalhador e o tomador dos serviços.

A idéia de colaboração está diretamente vinculada às anteriores quando se fala em trabalho parassubordinado, na medida em que pressupõe uma ligação funcional entre a atividade do prestador dos serviços e aquela do destinatário da prestação profissional.

A atividade do trabalhador é indispensável para que o tomador possa atingir os fins sociais ou econômicos que persegue. Os resultados produtivos da atividade do colaborador devem se unir aos da atividade do próprio tomador dos serviços, observando para tanto critérios qualitativos, quantitativos e funcionais.

\section{Coordenação do trabalho.}

Partindo desse elemento de colaboração entre os sujeitos da relação jurídica, assume relevância a idéia de coordenação, no sentido de uma peculiar modalidade de organização da prestação dos serviços.

Genericamente, o trabalho continua a ser prestado com autonomia, mas a sua organização é vinculada à atribuição de algum tipo de poder de controle e de coordenação a cargo do tomador dos serviços.

Mattia Persiani assevera que a idéia de coordenação é fundamental para entender esse tipo de relação jurídica, a ponto de preferir o uso da expressão trabalho "coordenado". considerada mais "elegante" que trabalho parassubordinado"

No trabalho "coordenado" diferentemente do que ocorre no trabalho subordinado, a atividade laboral é prometida pelo trabalhador tendo em vista um programa que é consensualmente definido ${ }^{6}$

O trabalhador não-promete a sua atividade pessoal para o desenvolvimento de qualquer objetivo pretendido pelo tomador, mas sim coloca os seus serviços à disposição somente daquele específico tipo de atividade, que é a necessária para atingir os fins previstos no programa contratualmente elaborado.

Essa situação é encontrada com freqüiência quando, no trabalho autônomo, o trabalhador se obriga a realizar uma obra determinada, prevista em contrato.

Mas o que importa ressaltar é justamente a possibilidade de a atividade de colaboração do trabalhador vir a ser prevista em um contrato de trabalho, tendo em

5. PERSIANI, Mattia. Autonomia, Subordinazione e Coordinamento nei recenti modelli d collaborazione lavorativa, II Diritto del Lavoro, Roma, 1998, p. 204

6. idem, p. 209 
vista o objetivo de atingir uma série de resultados. Aí reside, justamente, a importância da coordenação, pois permite a diferenciação tanto da subordinação quanto da autonomia.

Coordenação, então, surge com o sentido de "ordenar juntos": significa que ambas as partes possuem medidas a propor para alcançar o objetivo comum.

No trabalho subordinado, o trabalhador se sujeita ao poder de direção do empregador, devendo cumprir todas as determinações deste. Não há coordenação.

No trabalho autônomo, os serviços devem ser executados em conformidade com as condições previstas em contrato. $\mathrm{O}$ trabalhador deve realizar a obra ou o serviço, a fim de entregar o resultado contratualmente prometido. Também não há coordenação.

Veja-se que tanto no caso do trabalho subordinado quanto no do trabalho autônomo, o trabalhador deve cumprir certas instruções, que são vinculantes em relação às necessidades do tomador dos serviços.

Ocorre que o poder de dar instruções é diferente do poder de coordenar a prestação dos serviços.

As instruções pressupõem a existência de níveis distintos entre quem as dá e quem as recebe.

Já a coordenação se enquadra em níveis que se unem e até mesmo se sobrepõem. Exatamente por isso, surge a necessidade de prestador e tomador de serviços "ordenarem juntos" todo o trabalho, o que pode levar a modificações do programa contratual na medida em que este está sendo desenvolvido.

Como explica Mattia Persiani, o exercício desse poder de coordenação pode influir sobre as modalidades de execução da atividade contratualmente prometida, assim como sobre as próprias características da obra ou do serviço, com o objetivo de adequá-las às mutáveis exigências do seu beneficiário final - o que, aliás, é uma conseqüência da continuidade do contrato.

No limite, a coordenação pode até resultar na modificação do programa consensualmente estabelecido ou na alteração do objeto do contrato ${ }^{7}$

7. Distinção entre o trabalho subordinado e o parassubordinado.

Luisa Galantino ressalta que a essência da subordinação consiste na colaboração do trabalhador com a empresa, pela inserção "estrutural" de sua atividade na organização empresarial, visando alcançar os fins produtivos. Já na parassubordinação, a prestação laboral é coordenada em um caráter meramente "funcional" e não "estrutural"s

Giuseppe Santoro Passarelli mostra que a idéia de coordenação indica uma coligação funcional entre a prestação laboral e a atividade desenvolvida pelo destinatário desse trabalho. Ocorre que, diferentemente do trabalho subordinado, o

7. idem, p. 210

8. GalantinO, Luisa. Dirilto del Lavoro, Torino, G. Giappichelli Editore, 1996, p. 94-96 
trabalho coordenado não exclui as possibilidades de o prestador dos serviços determinar autonomamente ou de acordo com o tomador não apenas as modalidades, mas também o lugar e o tempo de adimplemento da prestação laboral ${ }^{9}$

O fato de o trabalhador parassubordinado organizar a sua própria atividade não-contrasta com a circunstância de que venha a ser utilizada pelo tomador dos serviços no momento em que este, considerando-a como um fator individual, a conjugue com outras atividades desenvolvidas por outros sujeitos, estranhos à relação juridica. Isso se explica justamente porque o tomador persegue um resultado que supera a utilidade instrumental decorrente da relação juridica singular mantida com o trabalhador parassubordinado.

Disso resulta substancial diferença em relação ao empregado, uma vez que este fica submetido ao poder diretivo do empregador, entendido como o poder de determinar tanto o comportamento devido quanto as modalidades de execução e disciplina do trabalho.

Já o prestador de trabalho coordenado, como o trabalhador autônomo, não está obrigado a permanecer na espera de ordens provenientes do tomador dos seus serviços nem a ficar à disposição deste. Somente se obriga a estabelecer o modo, o tempo e o lugar de execução da prestação laboral ajustada quando o tomador solicita o respectivo adimplemento.

8. Formas de trabalho parassubordinado no Direito italiano.

A doutrina italiana enfrenta certa dificuldade para efetuar uma classificação sistemática das formas de trabalho parassubordinado, tendo em vista a enorme variedade encontrada na prática. Senão, vejamos.

\section{1. contrato de agência.}

É um contrato de natureza contínua, em que uma das partes assume a obrigação de promover, por conta da outra, mediante remuneração, a conclusão de negócios em uma zona determinada.

A figura do agente é amplamente difundida nos setores do comércio e da prestação de serviços.

Giuseppe Ferraro alerta que muito freqüentemente o contrato de agência busca esconder uma relação de trabalho subordinado, gerando então ações contenciosas de grandes proporções ${ }^{10}$

A continuidade é elemento comum tanto ao contrato de agência quanto ao de trabalho subordinado; a diferença substancial entre eles reside na organização da

9. SANTORO PASSARELLI, Giuscppc. Il Lavoro Parasubordinato, Milano, Franco Angcli Editorc, 1979 , p. $66-67$

10. FERRARO, Giuscppc. I contratti di lavoro (ob.cit), p.233 
atividade do agente e no campo de interesses dela derivados. O agente assume a feição de um pequeno empreendedor, com uma capacidade própria de atuação, sem a sujeição ao poder diretivo.

Giuseppe Santoro Passarelli ressalta a diferente estrutura legal entre as duas formas de relações jurídicas, demonstrando que o contrato de agência se fundamenta na assunção dos riscos do empreendimento pelo agente, que expõe o seu próprio patrimônio aos resultados do trabalho."

A jurisprudência exclui a relação de parassubordinação na hipótese de o agente assumir a forma de uma sociedade comercial, ainda que o trabalho pessoal do sócio predomine na realização do objetivo social sobre outros fatores e sobre o valor do capital.

A razão de tal exclusão reside no fato de que a sociedade comercial possui uma subjetividade jurídica que a diferencia dos seus sócios, o que resulta na impossibilidade de uma prestação de serviços em que prevaleça a pessoalidade.

Por outro lado, a existência de uma sociedade de fato ou de uma firma individual não são fatores que excluam, por si só, o requisito da pessoalidade do trabalho. Sendo assim, nessas condições o agente poderá ser considerado trabalhador parassubordinado.

Também não se cogita da exclusividade no desenvolvimento das atividades, uma vez que esta é considerada um elemento não essencial do contrato de agência.

\section{2. contrato de representação comercial.}

É semelhante ao contrato de agência, pois o representante comercial tem igualmente a obrigação fundamental de promover negócios para o representado em certa zona de atuação. Para tanto, deverá se auto-organizar, visando ao cumprimento das atividades.

A principal diferença reside no fato de que o representante possui discricionariedade para estipular os respectivos contratos, dispondo assim de maior autonomia na conclusão dos negócios.

8.3. relações de colaboração.

A maior dificuldade prática na definição das hipóteses que se enquadram no conceito de parassubordinação é justamente o estabelecimento das "relações de colaboração"

É bastante comum a inclusão de profissionais liberais nessa área da parassubordinação, sempre que presentes os requisitos legais acima enunciados. 
É o que ocorre quando existem convenções em virtude das quais os profissionais se obriguem a colaborar por um certo periodo de tempo e sob determinadas condições de serviço com entes públicos ou privados, acatando um programa estipulado.

Nesse caso se encontram, por exemplo, serviços de assistência mantidos por determinadas sociedades, em que médicos colocam a sua atividade pessoal à disposição dos sócios, sempre que requisitados, em conformidade com a previsão da convenção.

Também com os advogados pode se configurar relação de parassubordinação, para serviços de consultoria jurídica, com a redação de contratos e pareceres, solução de dúvidas legais, resposta a questionamentos, mediante contrato que estabeleça a continuidade. Ou com engenheiros e arquitetos, para assistência técnica e urbanística a órgãos públicos ou privados, com duração continuiada. Ou, ainda, com o médico do trabalho, vinculado de maneira estável à fábrica para a qual presta os seus serviços pessoais.

Não fica afastada a parassubordinação se o profissional liberal contar com o trabalho de auxiliares, desde que a função destes seja complementar ou meramente executiva em relação à daquele.

Vale dizer, para que se possa cogitar de uma relação de trabalho parassubordinado com um profissional liberal, é indispensável que este coloque o seu serviço pessoal, de forma predominante, à disposição do contratante, durante um período de tempo contínuo.

Lembre-se o art. 52 do Tratado da União Européia, que reconhece o direito de um cidadão comunitário se estabelecer em qualquer Estado-membro para o fim de desenvolver uma atividade autônoma de modo estável e continuado, sob idênticas condições definidas pela legislação nacional para os seus próprios cidadãos.

Como explica Luisa Galantino, esse direito implica a faculdade do profissional liberal de criar e conservar mais de um centro de atividades no território da Comunidade Européia, observadas as diretivas específicas no que concerne ao recíproco reconhecimento de diplomas, certificados e outros títulos ${ }^{12}$

Também é possível cogitar de uma relação de trabalho essencialmente autônoma, mas coordenada de maneira estável com uma atividade empresarial, de modo a assumir uma feição de parassubordinação.

O exemplo concreto seria o de um artesão, cuja produção é toda voltada para uma determinada empresa comercial (desde que presentes, claro, os requisitos da pessoalidade predominante e da continuidade).

Geram polêmica na Jurisprudência italiana as situações em que sócios prestam serviços às respectivas sociedades: poderiam configurar-se relações de parassubordinação?

12. GALANTINO, Luisa. La Disciplina Comunitaria delle Libere Professioni, Il Diritto del Lavoro, Roma, 1999, p. 17-18 
Alguns julgados entendem que sim, desde que a atividade laboral seja diversa e estranha àquela que esse sócio esteja obrigado a prestar em função do próprio ato constitutivo da sociedade.

Também é possivel a parassubordinação na relação jurídica que une a sociedade e o administrador por ela contratado, desde que a situação de fato se enq̨uadre nos requisitos legais, não resvalando para um vínculo empregatício.

Em suma, são várias as situações que podem ser classificadas como relações de colaboração, resultando daí a amplitude do campo da parassubordinação em conformidade com o ordenamento jurídico italiano.

9. Conclusão.

O conceito de parassubordinação pode ser útil para a reformulação do sistema de relações de trabalho no Brasil, desde que seja utilizado com o objetivo de ampliar as formas de contratação de trabalho.

Além do trabalho subordinado (prestado por empregados) e do trabalho autônomo, surgiria o trabalho parassubordinado como uma nova forma de relação jurídica, que mereceria então uma regulamentação especial, adequada às peculiaridades de certas atividades em que a coordenação surge como elemento aglutinador do trabalhador e do tomador dos serviços.

São Paulo, maio de 2002.

10. Bibliografia.

FERRARO, Giuseppe. I contratti di lavoro, Padova, CEDAM, 1991.

GALANTINO, Luisa. Diritto del Lavoro, Torino, G. Giappichelli Editore, 1996.

GALANTINO, Luisa. La Disciplina Comunitaria delle Libere Professioni, 11 Diritto del Lavoro, Roma, 1999.

PERSIANI, Mattia. Autonomia, Subordinazione e Coordinamento nei recenti modelli di collaborazione lavorativa, Il Diritto del Lavoro, Roma, 1998.

SANTORO PASSARELLI, Giuseppe. Il Lavoro Parasubordinato, Milano, Franco Angeli Editore, 1979.

TARZIA, Giuseppe. Manuale del Processo del Lavoro, Milano, Giuffrè, 1987. 